\title{
A comparison of the perioperative outcomes of anterior surgical techniques for the treatment of multilevel degenerative cervical myelopathy
}

\author{
Jetan H. Badhiwala, MD, Sean N. Leung, BHSc, Yosef Ellenbogen, BHSc, \\ Muhammad A. Akbar, MD, Allan R. Martin, MD, PhD, Fan Jiang, MD, \\ Jamie R. F. Wilson, BMBCh, BA, Farshad Nassiri, MD, Christopher D. Witiw, MD, MS, \\ Jefferson R. Wilson, MD, PhD, and Michael G. Fehlings, MD, PhD, FRCS(C) \\ Division of Neurosurgery and Spinal Program, Department of Surgery, University of Toronto, Ontario, Canada
}

\begin{abstract}
OBJECTIVE Degenerative cervical myelopathy (DCM) is the most common cause of spinal cord dysfunction in adults. Multilevel ventral compressive pathology is routinely managed through anterior decompression and reconstruction, but there remains uncertainty regarding the relative safety and efficacy of multiple discectomies, multiple corpectomies, or hybrid corpectomy-discectomy. To that end, using a large national administrative healthcare data set, the authors sought to compare the perioperative outcomes of anterior cervical discectomy and fusion (ACDF), anterior cervical corpectomy and fusion (ACCF), and hybrid corpectomy-discectomy for multilevel DCM.
\end{abstract}

METHODS Patients with a primary diagnosis of DCM who underwent an elective anterior cervical decompression and reconstruction operation over 3 cervical spinal segments were identified from the 2012-2017 National Surgical Quality Improvement Program database. Patients were separated into those undergoing 3-level discectomy, 2-level corpectomy, or a hybrid procedure (single-level corpectomy plus additional single-level discectomy). Outcomes included 30-day mortality, major complication, reoperation, and readmission, as well as operative duration, length of stay (LOS), and routine discharge home. Outcomes were compared between treatment groups by multivariable regression, adjusting for age and comorbidities (modified Frailty Index). Effect sizes were reported by adjusted odds ratio (aOR) or mean difference (aMD) and associated $95 \%$ confidence interval.

RESULTS The study cohort consisted of 1298 patients; of these, 713 underwent 3-level ACDF, 314 2-level ACCF, and 271 hybrid corpectomy-discectomy. There was no difference in 30-day mortality, reoperation, or readmission among the 3 procedures. However, on both univariate and adjusted analyses, compared to 3-level ACDF, 2-level ACCF was associated with significantly greater risk of major complication (aOR 2.82, $p=0.005$ ), longer hospital LOS (aMD 0.8 days, $p=$ 0.002 ), and less frequent discharge home (aOR $0.59, p=0.046$ ). In contrast, hybrid corpectomy-discectomy had comparable outcomes to 3-level ACDF but was associated with significantly shorter operative duration (aMD -16.9 minutes, $p$ $=0.002$ ).

CONCLUSIONS The authors found multiple discectomies and hybrid corpectomy-discectomy to have a comparable safety profile in treating multilevel DCM. In contrast, multiple corpectomies were associated with a higher complication rate, longer hospital LOS, and lower likelihood of being discharged directly home from the hospital, and may therefore be a higher-risk operation.

https://thejns.org/doi/abs/10.3171/2020.4.SPINE191094

KEYWORDS degenerative cervical myelopathy; anterior cervical decompression and fusion; cervical spondylotic myelopathy; cervical spine; corpectomy; discectomy; ossification of the posterior longitudinal ligament; spinal fusion

ABBREVIATIONS ACCF = anterior cervical corpectomy and fusion; $\mathrm{ACDF}$ = anterior cervical discectomy and fusion; aMD = adjusted mean difference; aOR = adjusted odds ratio; $\mathrm{CHF}=$ congestive heart failure; $\mathrm{COPD}=$ chronic obstructive pulmonary disease; $\mathrm{CPT}=$ Current Procedural Terminology; $\mathrm{DCM}=$ degenerative cervical myelopathy; DVT = deep vein thrombosis; ICD-9/10-CM = International Classification of Diseases, Ninth/Tenth Revision, Clinical Modification; LOS = length of stay; MI = myocardial infarction; $\mathrm{mJOA}=$ modified Japanese Orthopaedic Association; NSQIP = National Surgical Quality Improvement Program; PE = pulmonary embolism.

SUBMITTED September 12, 2019. ACCEPTED April 6, 2020.

INCLUDE WHEN CITING Published online June 12, 2020; DOI: 10.3171/2020.4.SPINE191094. 
$\mathrm{D}$ EGENERATIVE cervical myelopathy (DCM) encompasses a spectrum of degenerative conditions of the cervical spinal column, resulting in chronic compression and injury of the spinal cord, and clinical loss of functional abilities. ${ }^{1}$ DCM is the most common cause of spinal cord impairment among adults, and is a disorder of growing public health relevance in the context of the aging global population. ${ }^{2}$ There is robust evidence that surgical decompression for DCM is safe, halts progression of neurological deficits, and improves functional status and quality of life $; 3$ surgery has thus become the standard of care for DCM, particularly for patients with moderate or severe myelopathy-related functional impairment. ${ }^{1,5}$

The choice of surgical approach for the treatment of DCM is principally guided by the relevant pathoanatomy. Anterior approaches are suitable to address predominantly ventral compressive pathology or to restore cervical lordosis. In the setting of multilevel DCM, an anterior decompression and reconstruction operation could involve multiple discectomies, corpectomies, or a combination of the two, and which of these provides the optimal result is unclear. ${ }^{6}$ Anterior cervical discectomy and fusion
(ACDF) permits adequate decompression of the spinal cord and segmental fixation with minimal blood loss and low risk of graft complication; however, the larger number of bone-to-graft interfaces increases the risk of pseudarthrosis. ${ }^{7-11}$ In contrast, anterior cervical corpectomy and fusion (ACCF) allows more complete decompression, especially in the setting of significant retrovertebral disease, and delivers greater fusion potential, but there may be a higher risk of complications and graft migration. ${ }^{6,12}$ Hybrid corpectomy-discectomy constructs may leverage the strengths of both techniques (Fig. 1). The comparative safety and efficacy of ACDF, ACCF, and hybrid corpectomy-discectomy for multilevel DCM remains unclear; very few studies have directly compared all 3 treatment approaches, and those that have have reported mixed results. ${ }^{13-15}$ Knowledge of the relative impact of these 3 procedures on patient in-hospital course and short-term outcomes in particular is lacking-yet, this information is critical to guide patient counseling and clinical decisionmaking. To that end, using data derived from a large North American administrative healthcare data set, we sought to compare the short-term outcomes of ACDF versus ACCF
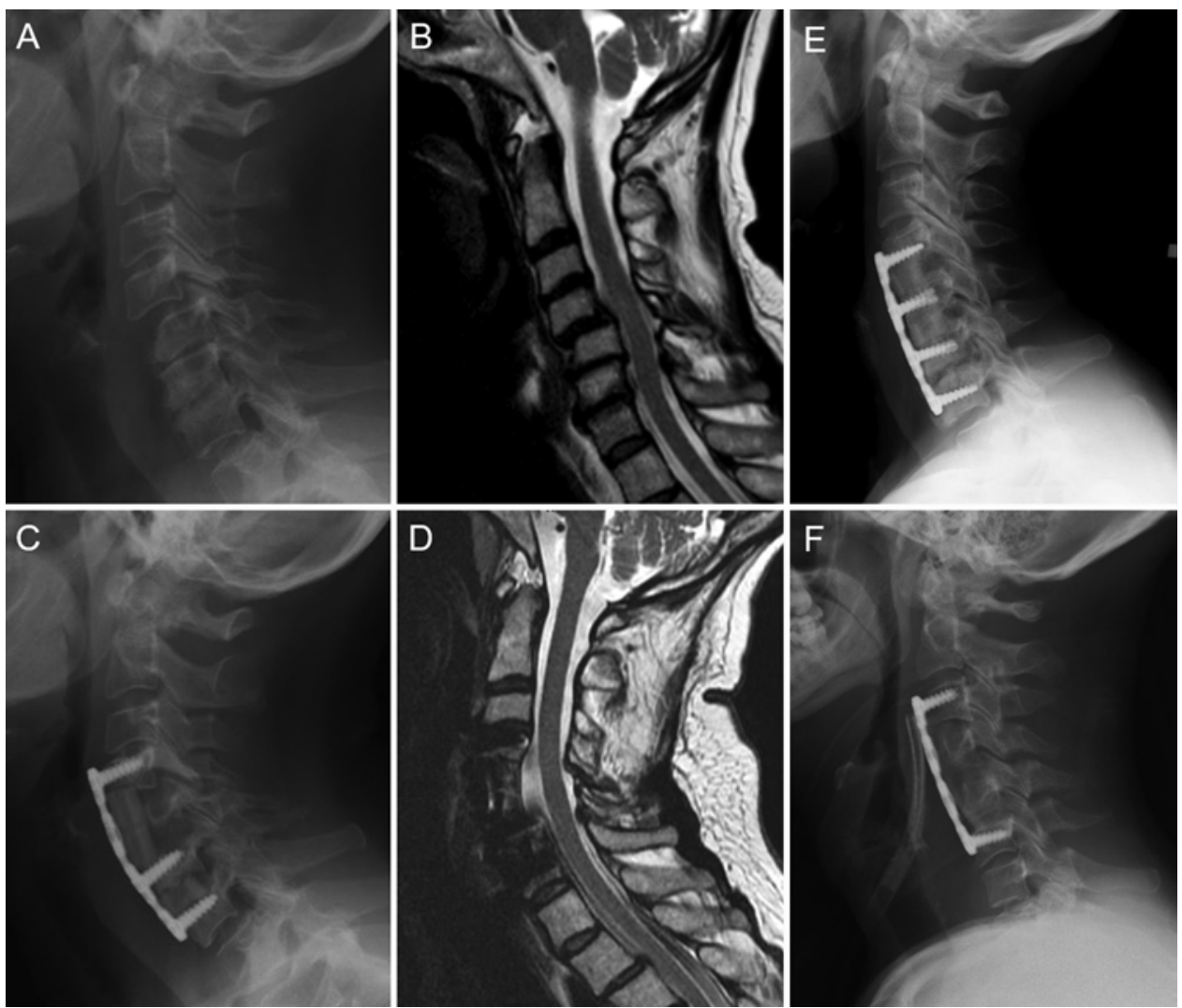

FIG. 1. Illustrative case examples. A-D: This patient presented with a history of progressive bilateral hand numbness and unsteady gait (mJOA score 15). Preoperative sagittal radiography and MRI (A and B) demonstrated multilevel spondylotic changes within the cervical spine spanning C4-7, with anterolisthesis at C4-5, retrolisthesis of C5, and a focal subaxial kyphosis. In addition to static factors, there was believed to be a strong dynamic component to this patient's spondylotic spinal cord compression. The patient was treated with a C5 corpectomy and C6-7 discectomy with reconstruction, with a fibular strut graft spanning C4-6, allograft spacer at C6-7, and anterior plate fixation. Postoperative sagittal radiography and MRI (C and D) demonstrated good decompression and restoration of cervical lordosis. E: Postoperative sagittal radiograph of a patient who underwent a 3-level ACDF. F: Postoperative sagittal radiograph of a patient who underwent a 2-level ACCF. Note: these patients' clinical history and imaging were not derived from the NSQIP database. 
TABLE 1. Pertinent ICD-9/10-CM and CPT codes

\begin{tabular}{ccl}
\hline Coding System & Code & \\
\hline ICD-9-CM & 721.1 & Cervical spondylosis with myelopathy \\
\cline { 2 - 3 } & 722.71 & Intervertebral disc disorder with myelopathy, cervical region \\
\hline ICD-10-CM & M47.12 & Other spondylosis with myelopathy, cervical region \\
\cline { 2 - 3 } & M50.0* & Cervical disc disorder with myelopathy \\
\hline CPT & 22551 & $\begin{array}{l}\text { Arthrodesis, anterior interbody, including disc space preparation, discectomy, osteophytectomy and decompression of } \\
\text { spinal cord and/or nerve roots; cervical below C2; + each additional interspace 22552 }\end{array}$ \\
\cline { 2 - 3 } & 226081 & $\begin{array}{l}\text { Vertebral corpectomy (vertebral body resection), partial or complete, anterior approach with decompression of spinal } \\
\text { cord and/or nerve root(s); cervical, single segment; + each additional segment 63082 }\end{array}$ \\
\cline { 2 - 3 } & $\begin{array}{l}\text { Arthrodesis, posterior or posterolateral technique, single level; cervical below C2 segment; + each additional vertebral } \\
\text { segment 22614 }\end{array}$ \\
\cline { 2 - 3 } 22842 & $\begin{array}{l}\text { Posterior segmental instrumentation (e.g., pedicle fixation, dual rods with multiple hooks and sublaminar wires); 3-6 } \\
\text { vertebral segments }\end{array}$ \\
\hline
\end{tabular}

versus hybrid corpectomy-discectomy in patients with multilevel DCM.

\section{Methods \\ Data Source}

The data source for this study was the American College of Surgeons (ACS) National Surgical Quality Improvement Program (NSQIP) database for the years 20122017. The NSQIP data sets encode surgical procedures by Current Procedural Terminology (CPT) codes and diagnoses by International Classification of Diseases, Ninth/ Tenth Revision, Clinical Modification (ICD-9/10-CM) codes. The NSQIP collects preoperative through 30-day postoperative data on randomly assigned patients at participating hospitals. Quality and reliability of the data are ensured through rigorous training of data abstractors and interrater reliability audits of participating sites. ${ }^{16}$ IRB approval was not required for this study, which relied on deidentified data derived from a national administrative healthcare data set.

\section{Patient Population}

We identified patients with a primary diagnosis of DCM (ICD-9-CM code 721.1 or 722.71 , ICD-10-CM code M47.12 or M50.0*) who underwent an anterior cervical decompression and fusion operation over 3 spinal segments. Patients were segregated into 3 groups: 1) 3-level discectomy (CPT code $22551+22552+22552$ ); 2) 2-level corpectomy (CPT code $63081+63082)$; and 3) hybrid construct with a single-level corpectomy and additional single-level discectomy (CPT code $63081+22551$ ). ICD-9/10-CM and CPT codes used for this study are summarized in Table 1. To minimize heterogeneity in the patient population, we included only elective operations performed on patients who were functionally independent at baseline. Furthermore, patients who underwent an additional posterior cervical operation (CPT code 22600 or 22842) were excluded.

\section{Baseline Characteristics}

Data relating to baseline demographic characteristics and comorbidities were extracted. Comorbidities were distilled into a modified Frailty Index, as has been reported previously using NSQIP variables,${ }^{17}$ following the methodology described by Searle et al. ${ }^{18}$ Specifically, 5 factors within the NSQIP (functional dependence, diabetes, history of chronic obstructive pulmonary disease [COPD], history of congestive heart failure $[\mathrm{CHF}]$, and hypertension) map to the original Canadian Study of Health and Aging Frailty Index. ${ }^{19}$ For each patient, each of these 5 factors (deficits) was coded as absent (0) or present (1). The mean score across all deficits was calculated, resulting in an index ranging from 0 (least frail) to 1 (most frail).

\section{Outcomes}

Outcomes evaluated were 30-day mortality, major complication, unplanned reoperation (related to the principal procedure), and unplanned readmission (related to the principal procedure), as well as operative duration (minutes), total hospital length of stay (LOS; days), and routine discharge home. Major complication was a composite of pneumonia, deep vein thrombosis (DVT), pulmonary embolism (PE), cardiac event (myocardial infarction [MI] or cardiac arrest), need for blood transfusion, deep wound infection, stroke, and sepsis.

\section{Statistical Analysis}

All statistical analyses were performed using Stata (version 15, StataCorp LLC) with an a priori specified significance level of $\mathrm{p}=0.05$ (2-tailed). Descriptive statistics were given using mean and standard deviation (SD) for continuous variables and count and percentage for categorical variables. Baseline characteristics in the 3 treatment groups were compared by chi-square test for categorical variables and 1-way ANOVA for continuous variables.

Univariate (unadjusted) comparison of outcomes between 3-level ACDF, 2-level ACCF, and hybrid corpectomy-discectomy groups was conducted using the chisquare test (categorical outcomes) or 1-way ANOVA (continuous outcomes). Adjusted comparisons were by multivariable logistic (dichotomous outcomes) or linear (continuous outcomes) regression, controlling for age and 


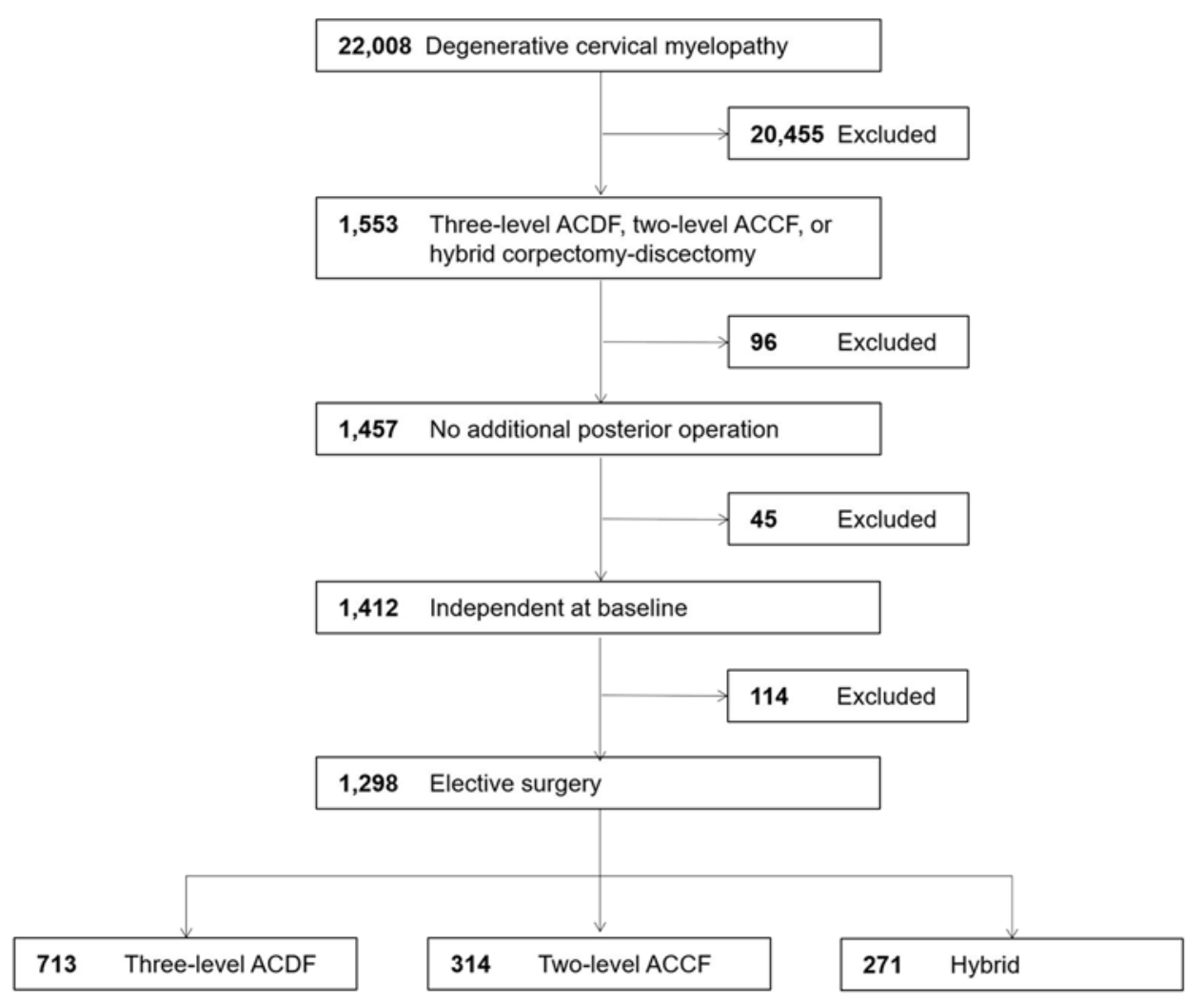

FIG. 2. Flowchart of patient eligibility and study enrollment.

modified Frailty Index as covariates. Effect sizes in adjusted analyses were summarized by adjusted odds ratio (aOR; dichotomous outcomes) or mean difference (aMD; continuous outcomes) and associated $95 \%$ confidence interval (CI).

\section{Results \\ Patient Cohort}

The study cohort consisted of 1298 patients with multilevel DCM who underwent an anterior cervical decompressive and reconstructive operation over 3 spinal segments: of these, 713 underwent 3-level ACDF, 314 2-level $\mathrm{ACCF}$, and 271 hybrid corpectomy-discectomy. A flowchart of patient eligibility is provided in Fig. 2. The mean patient age was 58.3 years. There were 672 males (51.8\%). Most patients were white $(979 ; 75.4 \%)$. With regard to comorbidities, a moderate number of patients had diabetes $(264 ; 20.3 \%)$ or were current smokers $(331 ; 25.5 \%)$, and a large proportion suffered from hypertension $(684 ; 52.7 \%)$. Baseline characteristics by treatment group are presented in Table 2; the corpectomy group had a significantly higher proportion of patients with diabetes and a slightly smaller proportion of patients who smoke.

\section{Outcomes}

Outcomes by treatment group and univariate (unadjusted) comparisons are presented in Table 3. Adjusted comparisons, controlling for age and comorbidities (modified Frailty Index) using multivariable regression, appear in Table 4. No significant difference was found in 30-day mortality, reoperation, or readmission between treatment groups; an adjusted analysis for mortality was not performed due to the prohibitively small number of events (4 deaths). On both unadjusted and adjusted analyses, compared to 3-level ACDF, 2-level ACCF was associated with greater risk of major complication $(5.7 \%$ vs $2.0 \%$; aOR $2.82,95 \%$ CI $1.36-5.82, \mathrm{p}=0.005)$, longer LOS ( 2.7 vs 1.9 days; aMD 0.8 days, $95 \%$ CI $0.3-1.3$ days, $\mathrm{p}=0.002$ ), and less frequent discharge home $(90.8 \%$ vs $94.7 \%$; aOR 0.59 , 95\% CI 0.35-0.99, $\mathrm{p}=0.046$ ). The difference in complication rate was driven primarily by a higher occurrence of pneumonia (2.6\% vs $0.7 \%$ ), DVT ( $1.3 \%$ vs $0.1 \%$ ), and blood transfusion $(1.9 \%$ vs $0 \%)$ with corpectomy. In contrast, hybrid corpectomy-discectomy had similar outcomes to 3-level ACDF, but was associated with shorter operative duration (153.4 vs 170.3 minutes, $p=0.007$; aMD -16.9 minutes, $95 \% \mathrm{CI}-27.4$ to -6.4 minutes, $\mathrm{p}=0.002$ ).

\section{Discussion}

This study assessed the short-term outcomes and inhospital course of 3 different anterior cervical procedures (3-level ACDF, 2-level ACCF, and hybrid corpectomydiscectomy) in patients with multilevel DCM. All 3 operations were generally well tolerated. Acute mortality was a very rare event and rates of reoperation and readmission were in the range of $2 \%-3 \%$. Three-level ACDF and hybrid corpectomy-discectomy had a similar safety profile, with the only significant difference in outcomes being a 
TABLE 2. Baseline characteristics by treatment group

\begin{tabular}{lcccc}
\hline \multicolumn{1}{c}{ Variable } & 3-Level ACDF $(\mathrm{n}=713)$ & 2-Level ACCF $(\mathrm{n}=314)$ & Hybrid $(\mathrm{n}=271)$ & $\mathrm{p}$ Value \\
\hline Mean age \pm SD, yrs & $58.7 \pm 10.5$ & $59.2 \pm 11.2$ & $56.2 \pm 10.9$ & 0.001 \\
\hline Males, $\mathrm{n}(\%)$ & $375(52.6)$ & $155(49.4)$ & $142(52.4)$ & 0.617 \\
\hline Race, $\mathrm{n}(\%)$ & & & & 0.070 \\
\hline White & $555(77.8)$ & $232(73.9)$ & $192(70.9)$ & \\
\hline Black & $88(12.3)$ & $55(17.5)$ & $48(17.7)$ \\
\hline Other/unknown & $70(9.8)$ & $27(8.6)$ & $31(11.4)$ & \\
\hline Comorbidities, $\mathrm{n}(\%)$ & & & & \\
\hline Diabetes & $133(18.6)$ & $80(25.5)$ & $51(18.8)$ & 0.034 \\
\hline Hypertension & $380(53.3)$ & $172(54.8)$ & $132(48.7)$ & 0.305 \\
\hline COPD & $39(5.5)$ & $18(5.7)$ & $7(2.6)$ & 0.131 \\
\hline CHF & $3(0.42)$ & $0(0)$ & $1(0.37)$ & 0.523 \\
\hline Steroid use & $25(3.5)$ & $9(2.9)$ & $13(4.8)$ & 0.446 \\
\hline Smoker & $180(25.3)$ & $68(21.7)$ & $83(30.6)$ & 0.045 \\
\hline Mean modified Frailty Index \pm SD & $0.16 \pm 0.15$ & $0.17 \pm 0.16$ & $0.14 \pm 0.15$ & 0.051 \\
\hline
\end{tabular}

slightly shorter operative duration (aMD -16.9 minutes) with the latter. Conversely, 2-level ACCF carried a higher rate of major complication (aOR 2.82), longer hospital LOS (aMD 0.8 days), and lower likelihood of being discharged directly home from hospital (aOR 0.59 ), indicating that it may be a comparatively higher-risk operation. In detailing the in-hospital course and safety outcomes of multiple discectomies, multiple corpectomies, and hybrid corpectomy-discectomy, this study addresses an important knowledge gap and provides information that clinicians may use to guide their discussions with patients on treatment options for DCM.

The question of the relative safety and efficacy of ACDF, ACCF, and hybrid corpectomy-discectomy for multilevel DCM is difficult to address using the current literature. First, the quality of the evidence is low, as it is mainly derived from single-center retrospective cohort studies. Second, many studies have focused strictly on comparing single-level ACCF to 2-level ACDF; however, the patients in these studies have relatively focal pathology spanning only 2 disc segments, which is not representative of the cases of more diffuse, multilevel spondylotic compression ( $\geq 3$ disc segments). ${ }^{20-22}$ Third, other studies have examined highly mixed populations that included patients with different numbers of operated levels (e.g., single or multiple corpectomies vs multiple discectomies $)^{23-26}$ or those who underwent an additional posterior operation. ${ }^{10}$ The substantial heterogeneity within these studies precludes sound conclusions from being drawn regarding comparative outcomes. A subset of studies and multiple meta-analyses have directly compared two of the three interventions of interest among patients undergoing ante-

TABLE 3. Unadjusted analysis of outcomes by treatment group

\begin{tabular}{lcccc}
\hline \multicolumn{1}{c}{ Outcome } & 3-Level ACDF $(\mathrm{n}=713)$ & 2-Level ACCF $(\mathrm{n}=314)$ & Hybrid $(\mathrm{n}=271)$ & $\mathrm{p}$ Value \\
\hline Mortality, $\mathrm{n}(\%)$ & $3(0.42)$ & $1(0.32)$ & $0(0)$ & 0.568 \\
\hline Reoperation, $\mathrm{n}(\%)$ & $12(1.7)$ & $9(2.9)$ & $4(1.5)$ & 0.371 \\
\hline Readmission, $\mathrm{n}(\%)$ & $22(3.1)$ & $9(2.9)$ & $6(2.2)$ & 0.764 \\
\hline Major complication, $\mathrm{n}(\%)$ & $14(2.0)$ & $18(5.7)$ & $5(1.9)$ & 0.002 \\
\hline Pneumonia & $5(0.70)$ & $8(2.6)$ & $2(0.74)$ & 0.030 \\
\hline DVT & $1(0.14)$ & $4(1.3)$ & $1(0.37)$ & 0.046 \\
\hline PE & $2(0.28)$ & $0(0)$ & $0(0)$ & 0.440 \\
\hline Ml or cardiac arrest & $3(0.42)$ & $4(1.3)$ & $0(0)$ & 0.090 \\
\hline Need for blood transfusion & $0(0)$ & $6(1.9)$ & $0(0)$ & $<0.001$ \\
\hline Deep wound infection & $0(0)$ & $0(0)$ & $1(0.37)$ & 0.150 \\
\hline Stroke & $2(0.28)$ & $0(0)$ & $0(0)$ & 0.440 \\
\hline Sepsis & $4(0.56)$ & $0(0)$ & $1(0.37)$ & 0.409 \\
\hline Mean operative duration \pm SD, mins & $170.3 \pm 70.4$ & $165.4 \pm 88.5$ & $153.4 \pm 66.9$ & 0.007 \\
\hline Mean LOS \pm SD, days & $1.9 \pm 4.6$ & $2.7 \pm 3.1$ & $2.0 \pm 2.1$ & 0.005 \\
\hline Routine discharge home, $\mathrm{n}(\%)$ & $675(94.7)$ & $285(90.8)$ & $263(97.1)$ & 0.004 \\
\hline
\end{tabular}


TABLE 4. Adjusted analysis of outcomes by treatment group

\begin{tabular}{lcccccc}
\hline \multirow{2}{*}{ Outcome } & \multicolumn{2}{c}{ 2-level ACCF $(\mathrm{n}=314)$} & & \multicolumn{2}{c}{ Hybrid $(\mathrm{n}=271)$} \\
\cline { 2 - 3 } \cline { 6 - 7 } & aOR or aMD $(95 \% \mathrm{Cl})^{*}$ & $\mathrm{p}$ Value & & aOR or aMD $(95 \% \mathrm{Cl})^{*}$ & $\mathrm{p}$ Value \\
\hline Mortality $\dagger$ & - & - & & - & - \\
\hline Reoperation & $1.66(0.69-4.00)$ & 0.257 & & $0.97(0.31-3.04)$ & 0.955 \\
\hline Readmission & $0.88(0.40-1.94)$ & 0.752 & & $0.79(0.32-1.99)$ & 0.621 \\
\hline Major complication & $2.82(1.36-5.82)$ & 0.005 & & $1.11(0.39-3.14)$ & 0.851 \\
\hline Operative duration, mins & $-5.3(-15.2$ to 4.6$)$ & 0.294 & & $-16.9(-27.4$ to -6.4$)$ & 0.002 \\
\hline LOS, days & $0.8(0.3-1.3)$ & 0.002 & & $0.2(-0.4$ to 0.7$)$ & 0.530 \\
\hline Routine discharge home & $0.59(0.35-0.99)$ & 0.046 & & $1.61(0.73-3.54)$ & 0.237 \\
\hline
\end{tabular}

* Adjusted for age and modified Frailty Index; 3-level ACDF is the reference group.

† Adjusted analysis not performed for mortality due to small number of events $(n=4)$.

rior decompression and reconstruction over 3 or more disc segments. ${ }^{27,28}$ Synthesizing the findings of these studies, the bulk of the literature suggests no difference in efficacy endpoints, including functional status (e.g., modified Japanese Orthopaedic Association [mJOA] score) and disability (e.g., Neck Disability Index), but fewer complications and less blood loss with ACDF or hybrid corpectomy-discectomy compared to ACCF. ${ }^{27,28}$ Still, there is heterogeneity in outcomes, and select studies have observed similar complication rates with ACCF and ACDF. ${ }^{10}$

Even fewer studies have directly compared all $3 \mathrm{ACDF}$, $\mathrm{ACCF}$, and hybrid corpectomy-discectomy procedures for multilevel ( $\geq 3$ disc segments) DCM. In a cohort of 120 patients who underwent 3-level ACDF ( $\mathrm{n}=43$ ), 2-level $\operatorname{ACDF}(n=24)$, or hybrid corpectomy-discectomy $(n=53)$, Guo et al. ${ }^{13}$ found no significant between-group difference with regard to improvement in JOA scores or fusion rate. However, ACCF was associated with a higher complication rate than ACDF (25.0\% vs 2.3\%), and higher blood loss $(209 \mathrm{ml})$ than ACDF $(143 \mathrm{ml})$ or hybrid corpectomydiscectomy $(162 \mathrm{ml})$. Furthermore, ACCF was associated with less improvement in $\mathrm{C} 2-7 \mathrm{Cobb}$ angle $\left(2.3^{\circ}\right)$ than hybrid corpectomy-discectomy $\left(9.4^{\circ}\right)$, which was associated with less improvement than $\mathrm{ACDF}\left(15.1^{\circ}\right)$. In a larger study encompassing more patients from the same center in China $(\mathrm{n}=180)$, Liu et al..$^{14}$ demonstrated comparable clinical efficacy, restoration of cervical lordosis, and complication rate between $\mathrm{ACDF}$ and hybrid corpectomydiscectomy. Although ACCF was associated with similar clinical improvements, it was associated with more bleeding, lower fusion rate, higher complication rate, and less improvement in cervical lordosis compared to ACDF and hybrid corpectomy-discectomy. In a third study of 98 patients from the same center, Wei et al. ${ }^{15}$ reported slightly conflicting findings, indicating better clinical outcomes with hybrid corpectomy-discectomy compared to ACDF and ACCF.

In this study, we have reported on a large North American cohort of patients. Taking our findings in the context of the current literature, hybrid corpectomy-discectomy appears to be a safe and effective alternative to 3-level ACDF. Conversely, congruent with previous studies, we found ACCF to be associated with a higher complication rate and greater blood loss. Whereas it is unclear from prior reports whether the greater bleeding risk with ACCF is of clinical significance, here we specifically observed a higher rate of blood transfusion, which is an important finding. Furthermore, while previous studies have focused specifically on surgery-related morbidity (such as CSF leak, epidural hematoma, and graft dislodgment), this is one of the few studies to offer an in-depth examination of general medical complications. Interestingly, the greater complication rate with ACCF observed in this study was driven primarily by a higher rate of pneumonia and DVT, complications associated with slower postoperative mobilization. Consistent with this finding, ACCF was also associated with a longer inpatient hospital LOS and less frequent discharge home from the hospital.

Our analysis benefits from the substantive statistical power provided by the NSQIP, which enrolls patients from more than 600 centers across Canada and the US. Our results should therefore be broadly generalizable, at least within the North American setting. Our study is strengthened by the use of rigorous criteria to define a specific and homogeneous population (3-level DCM) and set of interventions (i.e., 3-level ACDF, 2-level ACCF, or hybrid corpectomy-discectomy, with no additional posterior surgery) of interest, and the use of multivariable regression methods to adjust for relevant confounders in the analysis. Nonetheless, our study does have important limitations. First, implicit in this study is the assumption of equipoise; that is, we assume that for each enrolled patient, all 3 surgical interventions were equal and reasonable options. However, in reality, the individual pathoanatomy may have dictated the use of one approach over the others. For example, the presence of extensive retrovertebral disease may have driven the decision to pursue hybrid corpectomy-discectomy or 2-level ACCF. Without access to imaging data, we are unable to account for this factor. We therefore cannot discount the effects of selection bias, despite attempts to control for known and measured confounders. Related to this, although we attempted to control for comorbid status using the 5-factor modified Frailty Index, the NSQIP database does not contain information relating to the severity of these comorbidities; this is one possible source of residual confounding.

Second, the CPT codes used to identify interventions here have not been validated; however, these are generally believed to be more accurate than alternative coding systems (e.g., ICD-9/10-Procedure Coding System codes), 
because they are associated with billing. Third, the NSQIP was not specifically designed for spinal surgery; therefore, certain variables of interest are not captured. For example, we could not evaluate outcomes such as spinal alignment parameters, fusion rate, and surgery-specific complications (such as C5 nerve palsy, CSF leak, dysphagia, or hoarseness). Moreover, although we could examine 30-day patient morbidity and mortality, we could not assess efficacy endpoints or patient-reported outcomes (e.g., quality of life, pain, functional status, disability, or satisfaction) or long-term durability of the interventions (such as pseudarthrosis, adjacent-segment degeneration, and construct failure). Fourth, despite our large sample size, the number of events for certain outcomes (e.g., major complication) was low, making it more difficult to detect between-group differences. Finally, given the way the population of interest was defined in this study, the results are not generalizable to patients with even more extensive multilevel DCM, such as those with 4 disc segments.

\section{Conclusions}

We found hybrid corpectomy-discectomy to have a comparable in-hospital course and short-term safety profile to ACDF in treating multilevel DCM spanning 3 disc segments. In contrast, ACCF was associated with more frequent complications, longer hospital LOS, and lower likelihood of being discharged directly home from the hospital. Hybrid corpectomy-discectomy may therefore be considered a safe and reasonable alternative to ACDF, in which decompression must address a significant component of retrovertebral disease. By comparison, ACCF may represent a higher-risk operation and should be disfavored unless there is a strong indication based on individual pathoanatomy.

\section{References}

1. Nouri A, Tetreault L, Singh A, et al. Degenerative cervical myelopathy: epidemiology, genetics, and pathogenesis. Spine (Phila Pa 1976). 2015;40(12):E675-E693.

2. Kalsi-Ryan S, Karadimas SK, Fehlings MG. Cervical spondylotic myelopathy: the clinical phenomenon and the current pathobiology of an increasingly prevalent and devastating disorder. Neuroscientist. 2013;19(4):409-421.

3. Fehlings MG, Ibrahim A, Tetreault L, et al. A global perspective on the outcomes of surgical decompression in patients with cervical spondylotic myelopathy: results from the prospective multicenter AOSpine international study on 479 patients. Spine (Phila Pa 1976). 2015;40(17):1322-1328.

4. Fehlings MG, Wilson JR, Kopjar B, et al. Efficacy and safety of surgical decompression in patients with cervical spondylotic myelopathy: results of the AOSpine North America prospective multi-center study. J Bone Joint Surg Am. 2013;95(18):1651-1658.

5. Fehlings MG, Tetreault LA, Riew KD, et al. A clinical practice guideline for the management of patients with degenerative cervical myelopathy: recommendations for patients with mild, moderate, and severe disease and nonmyelopathic patients with evidence of cord compression. Global Spine J. 2017;7(3)(suppl):70S-83S.

6. Shamji MF, Massicotte EM, Traynelis VC, et al. Comparison of anterior surgical options for the treatment of multilevel cervical spondylotic myelopathy: a systematic review. Spine (Phila Pa 1976). 2013;38(22)(suppl 1):S195-S209.
7. Fountas KN, Kapsalaki EZ, Nikolakakos LG, et al. Anterior cervical discectomy and fusion associated complications. Spine (Phila Pa 1976). 2007;32(21):2310-2317.

8. Han YC, Liu ZQ, Wang SJ, et al. Is anterior cervical discectomy and fusion superior to corpectomy and fusion for treatment of multilevel cervical spondylotic myelopathy? A systemic review and meta-analysis. PLoS One. 2014;9(1):e87191.

9. Hilibrand AS, Fye MA, Emery SE, et al. Increased rate of arthrodesis with strut grafting after multilevel anterior cervical decompression. Spine (Phila Pa 1976). 2002;27(2):146-151.

10. Lau D, Chou D, Mummaneni PV. Two-level corpectomy versus three-level discectomy for cervical spondylotic myelopathy: a comparison of perioperative, radiographic, and clinical outcomes. J Neurosurg Spine. 2015;23(3):280-289.

11. Nirala AP, Husain M, Vatsal DK. A retrospective study of multiple interbody grafting and long segment strut grafting following multilevel anterior cervical decompression. $\mathrm{Br} J$ Neurosurg. 2004;18(3):227-232.

12. Wang JC, Hart RA, Emery SE, Bohlman HH. Graft migration or displacement after multilevel cervical corpectomy and strut grafting. Spine (Phila Pa 1976). 2003;28(10):1016-1022.

13. Guo Q, Bi X, Ni B, et al. Outcomes of three anterior decompression and fusion techniques in the treatment of three-level cervical spondylosis. Eur Spine J. 2011;20(9):1539-1544.

14. Liu Y, Hou Y, Yang L, et al. Comparison of 3 reconstructive techniques in the surgical management of multilevel cervical spondylotic myelopathy. Spine (Phila Pa 1976). 2012;37(23):E1450-E1458.

15. Wei L, Cao P, Xu C, et al. Comparison of three anterior techniques in the surgical treatment of three-level cervical spondylotic myelopathy with intramedullary T2-weighted increased signal intensity. World Neurosurg. 2019;126:e842e852.

16. Shiloach M, Frencher SK Jr, Steeger JE, et al. Toward robust information: data quality and inter-rater reliability in the American College of Surgeons National Surgical Quality Improvement Program. J Am Coll Surg. 2010;210(1):6-16.

17. Subramaniam S, Aalberg JJ, Soriano RP, Divino CM. New 5-factor modified frailty index using American College of Surgeons NSQIP data. J Am Coll Surg. 2018;226(2):173181.e8.

18. Searle SD, Mitnitski A, Gahbauer EA, et al. A standard procedure for creating a frailty index. BMC Geriatr. 2008;8:24.

19. Rockwood K, Song X, MacKnight C, et al. A global clinical measure of fitness and frailty in elderly people. CMAJ. 2005;173(5):489-495.

20. Huang ZY, Wu AM, Li QL, et al. Comparison of two anterior fusion methods in two-level cervical spondylosis myelopathy: a meta-analysis. BMJ Open. 2014;4(7):e004581.

21. Oh MC, Zhang HY, Park JY, Kim KS. Two-level anterior cervical discectomy versus one-level corpectomy in cervical spondylotic myelopathy. Spine (Phila Pa 1976). 2009;34(7):692-696.

22. Park Y, Maeda T, Cho W, Riew KD. Comparison of anterior cervical fusion after two-level discectomy or single-level corpectomy: sagittal alignment, cervical lordosis, graft collapse, and adjacent-level ossification. Spine J. 2010;10(3):193-199.

23. Burkhardt JK, Mannion AF, Marbacher S, et al. A comparative effectiveness study of patient-rated and radiographic outcome after 2 types of decompression with fusion for spondylotic myelopathy: anterior cervical discectomy versus corpectomy. Neurosurg Focus. 2013;35(1):E4.

24. Hwang SL, Lee KS, Su YF, et al. Anterior corpectomy with iliac bone fusion or discectomy with interbody titanium cage fusion for multilevel cervical degenerated disc disease. $J$ Spinal Disord Tech. 2007;20(8):565-570.

25. Katz AD, Mancini N, Karukonda T, et al. Comparative and predictor analysis of 30-day readmission, reoperation, and morbidity in patients undergoing multilevel ACDF vs single 
and multilevel ACCF using the ACS-NSQIP dataset. Spine (Phila Pa 1976). 2019;44(23):E1379-E1387.

26. Uribe JS, Sangala JR, Duckworth EA, Vale FL. Comparison between anterior cervical discectomy fusion and cervical corpectomy fusion using titanium cages for reconstruction: analysis of outcome and long-term follow-up. Eur Spine J. 2009; 18(5):654-662.

27. Liu JM, Peng HW, Liu ZL, et al. Hybrid decompression technique versus anterior cervical corpectomy and fusion for treating multilevel cervical spondylotic myelopathy: Which one is better? World Neurosurg. 2015;84(6):2022-2029.

28. Wang T, Wang H, Liu S, et al. Anterior cervical discectomy and fusion versus anterior cervical corpectomy and fusion in multilevel cervical spondylotic myelopathy: a meta-analysis. Medicine (Baltimore). 2016;95(49):e5437.

\section{Disclosures}

Dr. Jefferson Wilson reports being a consultant for Stryker Canada and Bioventus.

\section{Author Contributions}

Conception and design: Fehlings, Badhiwala, Leung. Acquisition of data: Badhiwala, Leung. Analysis and interpretation of data: Badhiwala, Leung, Ellenbogen, Akbar, Martin, Jiang, Wilson, Nassiri, Witiw, Wilson. Drafting the article: Badhiwala, Leung. Critically revising the article: all authors. Reviewed submitted version of manuscript: all authors. Administrative/technical/material support: Fehlings. Study supervision: Fehlings.

\section{Correspondence}

Michael G. Fehlings: University of Toronto, Toronto Western Hospital, Toronto, ON, Canada.michael.fehlings@uhn.ca. 